\title{
Mesurem la temperatura quan anem a la piscina
}

\author{
Laura de la Cruz Marcè (lauradlcm@gmail.com) Mestra de primària en pràctiques a l'Escola Sant Felip Neri \\ (Barcelona). \\ Víctor López Simó (victor.lopez@uab.cat) CRECIM i Departament de Didàctica de la Matemàtica i de les \\ Ciències Experimentals, UAB.
}

Presentem un conjunt d'activitats realitzades per alumnes de 1r de primària al voltant de la temperatura que hi ha als diferents espais que els infants visiten cada vegada que van a la piscina municipal. A través d'aquestes experiències els infants han pogut mesurar cada una de les temperatures amb la consola Ecodad, i han relacionat el resultat obtingut amb la roba que porten dins i fora de les instal-lacions.

Paraules clau: primària, ecodad, temperatura, piscina, mesures, recollida i treball de dades.

We present a set of activities carried out by first grade of elementary school students. These activities are focused on the temperature inside and outside a Swimming pool. Students measured the temperature using the data logger "Ecodad", and the obtained results were related with their clothing inside and outside the Swimming pool.

Key words: Elementary school, ecodad, temperature, swimming pool, data logging.

\section{INTRODUCCIÓ}

La classe dels pingüins de l'Escola Sant Felip Neri de Barcelona visiten setmanalment la piscina de Can Ricart, Centre Esportiu Municipal del Raval (Barcelona). Tots els nens i nenes de la classe saben que quan entren a la piscina fa molta calor, s'han de treure la roba i posar-se el banyador, i que al sortir s'han de vestir de nou, i que cal d'eixugar els cabells abans de sortir del vestuari. Si al carrer fa fred, a més, també caldrà posar-se l'abric o la jaqueta.

Però què canvia exactament quan som al carrer, al vestuari o dins la piscina? Podem mesurar d'alguna manera els canvis en el medi? I com podem representar aquesta informació? Per respondre aquestes preguntes s'ha utilitzat el sensor de temperatura que incorpora la consola Ecodad, a través de la qual l'experiència quotidiana d'anar a la piscina ha esdevingut una activitat experimental que s'ha convertit en el primer contacte d'aquest grup d'infants amb eines TIC com aquesta. De fet, eines com l'Ecodad són presents en algunes activi- tats experimental de coneixement del medi (Chivite, Màrquez, 2010; Carbó, Pigrau, Tarín, 2006), i presenten una oportunitat per contribuir a que els alumnes aprenguin ciències a través d'una manera particular de concebre els fenòmens del seu entorn: mesurant-los, representant-los i donant-li significat a partir de les seves idees prèvies.

\section{OBJECTIUS}

D'una banda, aquesta seqüència d'activitats té com a finalitat aconseguir que els alumnes aprenguin que podem mesurar la temperatura del nostre entorn, que això ens permet relacionar un valor numèric amb una sensació tèrmica (fred o calor), i que en funció de la temperatura hem d'adaptar la vestimenta (més roba o menys roba). Si la nostra vestimenta no es correspon amb la temperatura de l'entorn podem sentir-nos acalorats o bé passar fred.

Alhora, però, aquesta activitat també pretén iniciar als alumnes en el treball experimental i en les habilitats que comporta de manipular un sensor, fer 
lectures de valors, representar i classificar aquests valors i extreure'n conclusions.

\section{L'EXPERIĖNCIA PAS A PAS}

\section{Presentació del nroblema i planifica- ció de l’experiència}

En primer lloc vam fer els grups (de quatre alumnes cadascun), i vam introduir el problema discutint com anaven vestits pel carrer, si sabien quina temperatura podien estar, a partir del qual els alumnes van anar explicitant les seves prèvies. Posteriorment vam posar càrrecs a cada grup: secretari/a, ajudant i portador/a de l'aparell.

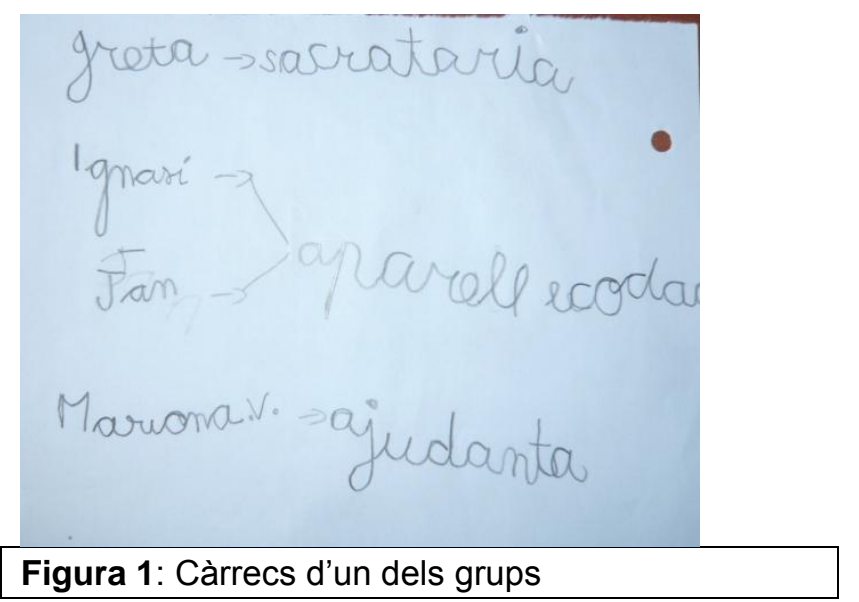

Aleshores vam omplir la fitxa on mostra amb més claredat la roba que portem quan anem pel carrer, al vestuari de la piscina i dins la piscina. Una vegada vam parlar de la temperatura en els diferents espais i vam omplir la fitxa vam treure les hipòtesis següents:

- A la piscina: podem anar despullats $i$ podem anar mullats perquè la temperatura és més alta.

- Al carrer: hem d'anar vestits i portar una jaqueta o un abric perquè la temperatura és més baixa.

- Als vestuaris: podem anar despullats o vestits $i$ quan sortim ens hem d'assecar els cabells.

En darrer lloc, vam parlar sobre la consola de sensors Ecodad. Cap alumne l'havia vist mai ni sabia com funcionava. Vam parlar de com havíem de trobar la mesura, com s'havia d'engegar i apagar i quines instruccions calia seguir [1].

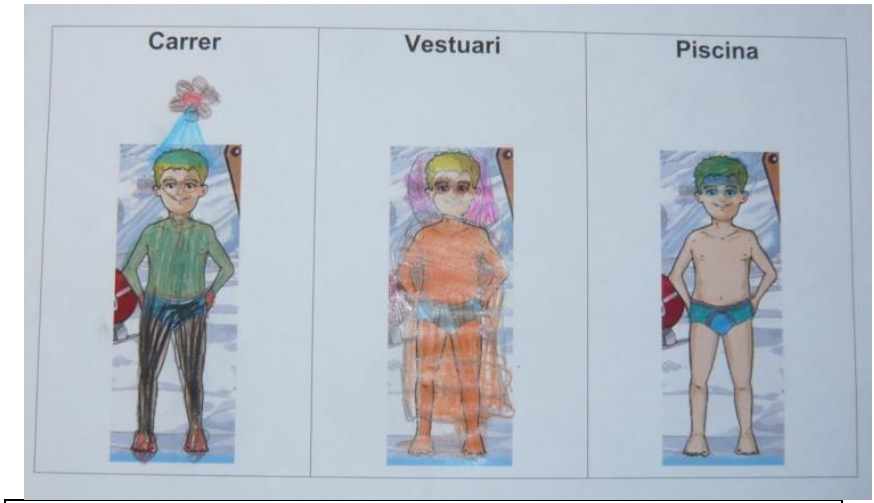

Figura 2: Producció dels nens com van vestits a la piscina, abans d'obtenir les dades.

\section{Mesura i representació de les dades}

El mateix dia vam adreçar-nos al complex municipal, vam entrar als vestuaris i una vegada estàvem preparats per anar a la piscina, amb els grups vam mesurar la temperatura dels vestuaris i de dins la piscina. Al tenir cada alumne un càrrec vam poder anar per feina, ja que cada alumne tenia present què havia de fer. Una vegada fora vam mesurar la temperatura del carrer. Amb totes les dades, cada grup va omplir una taula com la de la figura 3.

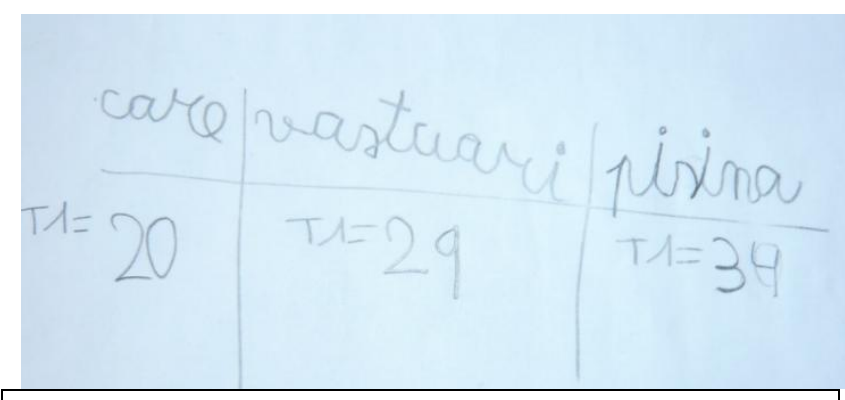

Figura 3: Taula amb les dades corresponents a la temperatura enregistrades dins i fora de la piscina.

\section{Comunicació dels resultats}

Per la tarda, vam anar a l'aula polivalent per parlar de l'experiència realitzada, i per discutir en grup què havia passat al fer les mesures de temperatura. Per fer-ho, vam repartir la mateixa fitxa que havíem fet al mati, però amb un petit canvi: Ara no només havien de dibuixar la roba que portarien en cada lloc, sinó també indicar el número de temperatura obtinguda, i també pintar el valor de la temperatura sobre un termòmetre, de manera que la superfície pintada fos major en les situacions on la temperatura era més altra. 


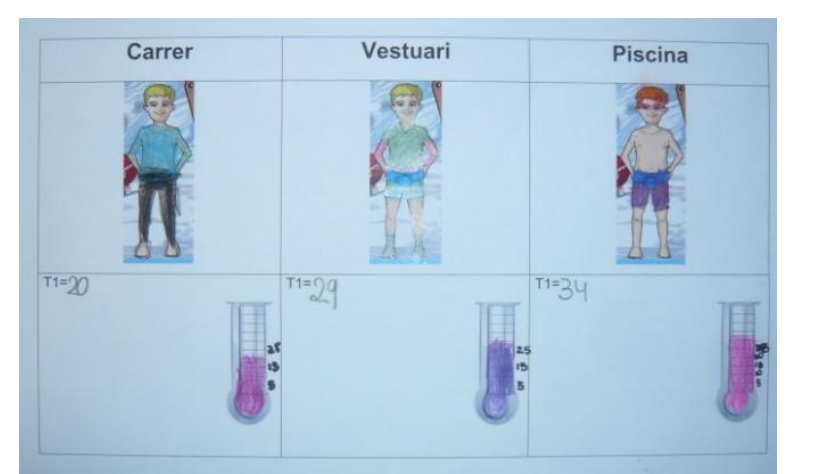

Figura 6: Producció dels nens com van vestits a la piscina, desprès d'obtenir les dades.
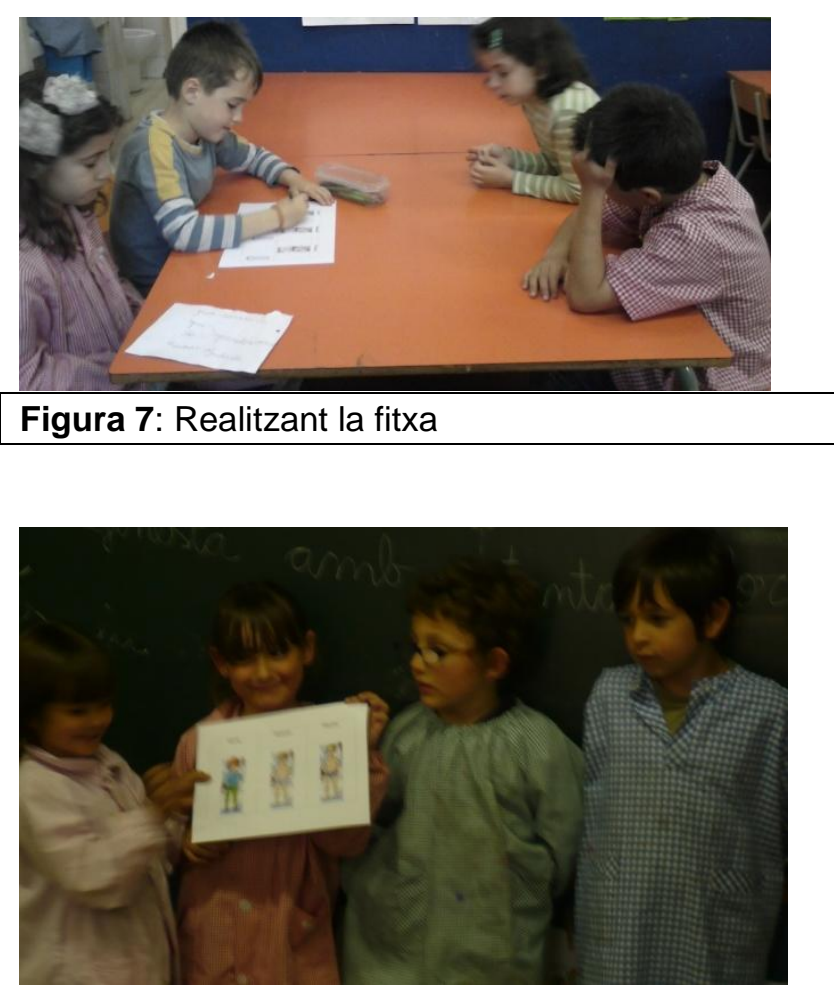

Figura 6: Explicació de l'experiència amb l'Ecodad a la resta de companys.

\section{Exposició davant dels companys}

Finalment, el grup d'alumnes van explicar a la resta de companys i mestres tot el que havien fet. A través d'aquesta exposició els infants van explicar com es podia mesurar la temperatura i com el valor mesurat estava relacionat amb la roba que portaven dins i fora la piscina.

\section{VALORACIÓ DE L’EXPERIÈNCIA}

Aquesta activitat va permetre als alumnes de la classe dels pingüins de l'escola Sant Felip Neri de Barcelona conèixer un nou aparell capaç de mesurar la temperatura. Cal tenir en compte que en la majoria de casos el valor numèric obtingut en la mesura era poc significatiu pels infants, o fins i tot mancava totalment de significat per ells. Ara bé, el fet de poder comparar diferents valors numèrics $i$ ordenar-los de major a menor, així com de representar la temperatura gràficament, va fer que a l'hora d'exposar davant els companys relacionessin l'experiència realitzada amb el seu coneixement quotidià: la roba que porten dins i fora la piscina. Per exemple una alumne va exposar: "Les temperatures que estan més altes fan calor i les temperatures baixes fa fred".

De fet, aquesta experiència va suposar una iniciació al treball experimental a través de la mesura amb valors numèrics, que va suposar una gran novetat per a la classe dels pingüins. Finalment, Tot $i$ que el treball amb sensors i valors numèrics és difícil per als primers anys de l'educació primària, aquesta iniciació d'una banda, obre la porta a futures activitats que permetin un major maneig tant dels aparells com de les dades que s'obté a través d'ells.

\section{REFERÈNCIES}

CARBÓ, C,. PIGRAU, T,. TARÍN, R.M. (2006). Pensar, experimentar i comunicar a l'aula de ciències, amb suport TIC a l'Educació Infantil $i$ Primària. Barcelona: Equip d'educació Infantil i Primària dels CESIRE-CDEC.

CHIVITE. J, MÀRQUEZ. C. (2010). Com influencia la temperatura en el creixement de les hortalisses en un hivernacle. Revista Ciències 17, 2-6.

[1] Funcionament Ecodad:

http://srvcnpbs.xtec.cat/cdec/images/stories/Aula_ci enci-

es_I_P/webmoticedodad/3_Manual_reduit_EcoDad _Modes_mesura.pdf 